\title{
大肠杆菌小 RNA SgrS 单分子原位成像方法的建立
}

\author{
王净 ${ }^{1,2}$, 韩延平 $2^{*}$, 杨瑞馥 ${ }^{2}$ \\ 1. 河北北方学院动物科技学院, 张家口 075131 ; \\ 2. 军事医学科学院微生物流行病研究所病原微生物生物安全国家重点实验室, 北京 100071 \\ *联系人, E-mail: hypiota@hotmail.com
}

2017-03-26 收稿, 2017-04-12 修回, 2017-04-12 接受, 2017-07-07 网络版发表

国家重点基础研究发展计划(2014CB744405)和河北省科技计划(16236605D-1(2017))资助

\begin{abstract}
摘要为了确定单分子 SgrS的空间定位, 在野生株Escherichia coli MG1655基础上, 构建敲除株 $\Delta \operatorname{sgrS}$ 和过表达 株 $\Delta s g r S$-pBAD-SgrS，并以3株菌为供试菌株建立了定位大肠杆菌 SgrS 的单分子荧光原位杂交(smFISH)方法. 优化 条件为: 杂交后细菌洗涤次数为 5 次, 涂片时加入SlowFade Diamond Antifade Mountant防淬灭, 细菌在杂交液和探 针的混合液中经 $40^{\circ} \mathrm{C}$ 杂交 $3 \mathrm{~h}$, 杂交前探针置 $98^{\circ} \mathrm{C}$ 变性 $10 \mathrm{~min}$, Alexa-555 WGA染料用来标记细胞壁. smFISH操作 步骤确定为: 固定-洗涤-透化-预杂交-杂交-洗涤-染细胞壁-洗涤-涂片, 最后使用 N-SIM超分辨率显微镜观察成像. 定位结果显示, SgrS 呈绿色点状荧光弥散分布于细菌胞浆中, Alexa-555 WGA染料标记细胞壁呈红色, 从而完整地 定位了大肠杆菌的形态. SmFISH方法和超分辨显微技术的结合可为深入研究细菌模式基因 sRNA的定位以及 sRNA介导的调控机制提供线索和技术支持.
\end{abstract}

关键词大肠杆菌, sRNA SgrS, 单分子荧光原位杂交, 超分辨率显微镜, Alexa-555 WGA

常用的分析基因表达方法有 qPCR、芯片和RNAseq, 这几种方法以细胞群体为研究对象, 结果都集 中于转录本丰度. 它们既不能提供特定RNA空间信 息, 也不能体现细胞间表达水平的差异. 单分子苂光 原位杂交(smFISH)是一种新的基因表达分析方法, 能通过空间定位报告转录本丰度 ${ }^{[1 \sim 4]}$. 其原理是利用 一些短的寡核苷酸互补目的基因, 在每个寡核苷酸 末端标记苂光基团，使得目的基因上有足够量的苂 光分子, 超高分辨率显微成像可见定位的苂光点.

非编码RNA转录在细胞功能、分化和疾病形成 等进程中扮演着重要角色, smFISH通过细胞内转录 的定位可以反映正常与疾病状态细胞表达水平的变 化, 这些信息对理解基因调控机制非常重要 ${ }^{[5,6]}$. Chou等人 ${ }^{[7]}$ 使用 $s m F I S H$ 方法以不同苂光共定位流感 病毒出芽前胞质中RNA, 揭示流感病毒感染周期中
的时空传播规律. Singer等人 ${ }^{[8]}$ 研究胚胎干细胞的 DNA甲基化的动态异质性，用单分子RNA FISH方法 定量分析单个胚胎干细胞基因表达以及随着时间推 移呈现的动态变化, 从而证明DNA甲基化在维持相 对稳定状态所起的关键作用. Sinsimer等人 ${ }^{[9]}$ 用 smFISH方法检测果蝇(Drosophila melanogaster)发育 成熟的卵母细胞中的内源 mRNA，先用苂光探针定 位遗传物质，再通过测定每一个探针的苂光强度定 量遗传物质.

2014年, Nature Methods将单分子技术和超高分 辨率显微成像列为十年的十大技术之一. $\mathrm{smFISH}$ 作 为一种新的实用方法主要用于真核生物, 在原核生 物中应用不多见，并且国内未见相关方法的报道. 由 于此新技术尚处于应用初期，许多技术手段有待完 善, 因此, 本研究以大肠杆菌 (Escherichia coli)

引用格式: 王净, 韩延平, 杨瑞馥. 大肠杆菌小 RNA SgrS 单分子原位成像方法的建立. 科学通报, 2017, 62: 2804-2813 Wang J, Han Y P, Yang R F. Development of the fluorescent imaging method of single-molecule sRNA SgrS in situ in Escherichia coli (in Chinese). Chin Sci Bull, 2017, 62: 2804-2813, doi: 10.1360/N972017-00351 
MG1655, $\Delta s g r S, \Delta s g r S-p B A D-S g r S 3$ 株菌为供试菌 株, 通过优化一系列条件, 建立 smFISH方法, 并与 N-SIM超分辨率显微镜相结合, 清晰地定位细菌中 的小RNA. 本方法旨在为RNA可视化的定量检测以 及基因动态变化的研究奠定技术基础, 从而揭示生 命活动规律和奇妙的生命现象.

\section{1 材料与方法}

\section{1 菌株、质粒和试剂}

Escherichia coli K-12 MG1655为军事医学科学 院生物工程研究所王恒樑老师赠送. pKD46质粒、改 造的pBAD载体、卡那霉素抗性盒为本实验室保存.

甲酰胺, $20 \times \mathrm{SSC}$, BSA购自 Ambion (美国); 核糖 核苷氧钒基复合物购自 New England Biolabs (美国); SlowFade ${ }^{\circledR}$ Diamond Antifade Mountant, Alexa-555 WGA, Alexa Fluor 488购自 Invitrogen Corporation (美 国); 硫酸葡聚糖、大肠杆菌tRNA购自 Sigma (美国).

\section{2 菌株构建}

(i ) 引物设计. 根据要敲除的SgrS基因外上下 游序列及卡那霉素抗性盒序列设计敲除用引物; 在 同源区域外侧和Kan盒基因内部分别设计上下游鉴 定引物; 在SgrS基因上下游设计过表达用引物, 分别 加人 EcoR I 和HindIII酶切位点(表1).

(ii) 敲除株 $\Delta s g r S$ 的构建. 使用一步同源重组 法构建大肠杆菌(Escherichia coli) K-12 MG1655敲除 株 $\Delta s g r S$. 提取 $\mathrm{pKD} 46$ 质粒电转至 $E$. coli K-12 MG1655 感受态细胞. 带有同源臂的引物对 SgrS-kan-F/R扩增
卡那霉素抗性盒, 将PCR产物进行纯化. 制备 E. coli K-12 MG1655/pKD46感受态细胞时加人 $L$-阿拉伯糖, 从而诱导Red重组酶, 当卡那需素抗性盒电转至感受 态细胞时, 卡那需素抗性盒经同源重组替代 $\operatorname{sgrS}$ 基 因, 通过进一步篮选得到敲除株. 辅助质粒pKD46为 温度敏感型, 菌液在 $42^{\circ} \mathrm{C}$ 条件下低速培养 $2 \mathrm{~h}$ 以消除 pKD46质粒.

（iii）过表达株 $\Delta s g r S$-pBAD-SgrS的构建. 利用 改造的 $\mathrm{pBAD}$ 载体 ${ }^{[10,11]}$ 将 $s g r S$ 与载体连接构建 pBAD-SgrS 重组质粒. 提取 pBAD 质粒, 以 $\mathrm{K}-12$ MG1655基因组为模板, SgrS-pBAD-F/R引物对扩增 带有酶切位点的 $s g r S$ 片段并进行胶回收纯化，双酶切 回收片段和 $\mathrm{pBAD}$ 质粒并进行连接, 连接产物转化 DH5 $\alpha$ 感受态细胞. 将pBAD空载体和构建的pBAD$\mathrm{SgrS}$ 质粒各 $1 \mu \mathrm{L}$ 电转至 $\Delta s g r S$ 中, 构建阴性对照菌株 $\Delta s g r S$-pBAD和过表达菌株, $\Delta s g r S$-pBAD-SgrS. 过表 达菌株培养过程中通过加人 $L$-阿拉伯糖进行诱导, 实现基因的过表达 ${ }^{[12]}$.

\section{3 smFISH方法的建立}

(i) 探针的合成与测定. 根据smFISH)原理(图 1(a)), 参考文献报道的E. coli K-12 MG1655小RNA Sgrs 9 条探针序列 ${ }^{[13]}$, 用mfold在线预测 $\mathrm{SgrS}$ 二级结 构(图1(b)), 在3'末端标记苂光染料Alexa Fluor 488, RNA探针送北京六合通经贸有限公司合成并标记. RNA探针加RNAse Free Water稀释至10 $\mu \mathrm{mol} / \mathrm{L}$ 备用. 使用Nano drop 2000 (Thermo) “Microarray”测定RNA $\left(\mu \mathrm{g} \mathrm{mL}{ }^{-1}\right)$ 和染料 $(\mu \mathrm{mol} / \mathrm{L})$ 浓度, 并用 $\mathrm{GraphPad}$ Prism软 件作图分析测定的Alexa Fluor 488浓度. 计算染料的标

表 1 引物设计 ${ }^{\mathrm{a}}$

Table 1 Design primers ${ }^{\text {a }}$

\begin{tabular}{ll}
\hline 引物名称 & 引物序列 $\left(5^{\prime} \rightarrow 3^{\prime}\right)$ \\
\hline SgrS-kan-F & CTAACGATGAAGCAAGGGGGTGCCCCATGCGTCAGTTTTATCGTGTAGGCTGGAGCTGCTTC \\
SgrS-kan-R & GCGCGGCGAGAATAAAAAAAACCAGCAGGTATAATCTGCTGGCGCATATGAATATCCTCCTTA \\
SgrS-I-F & CTAACGATGAAGCAAGGG \\
SgrS-I-R & CAATGTAGGAGCCTGTAGC \\
Kan-I-R & CATAGCCGAATAGCCTCTC \\
Kan-I-F & CTCCTGTCATCTCACCTTG \\
pKD46-F & CATCCATAGTTGCCTGACTC \\
pKD46-R & TCTTACGGATGGCATGACAG \\
SgrS-pBAD-F(EcoR I $)$ & CACGAATTCGATGAAGCAAGGGGGTGCCCCATGCGTCAG \\
SgrS-pBAD-R $($ HindIII $)$ & CCCAAGCTTAAAAAAAACCAGCAGGTATAATCTGCTGGCGGGTG \\
\hline
\end{tabular}

a) 下画线为同源臂序列; 斜体部分为卡那霉素抗性基因序列; 粗体部分为酶切位点 


\section{(a)}

(b)

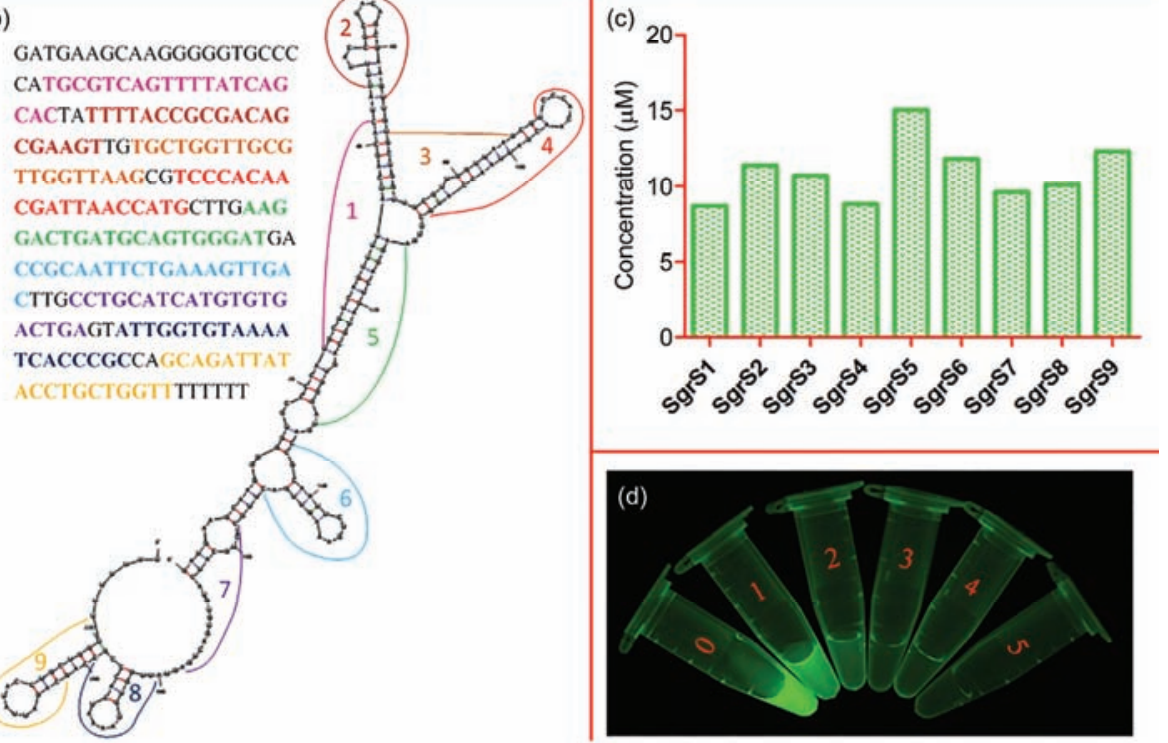

图 1 (网络版彩色)RNA探针的合成与测定. (a) smFISH原理; (b) mfold预测SgrS二级结构, 9 条探针分别用不同颜色标示; (c) Alexa Fluor 488 的 苂光浓度 $(R N A$ 浓度 $10 \mu \mathrm{mol} / \mathrm{L})$; (d) 不同洗涤次数下洗液荧光图片

Figure 1 (Color online) Synthesis and determination of RNA probes. (a) Principle of SmFISH; (b) predict SgrS secondary structure by mfold, nine colors indicate different probe, respectively; (c) fluorescent concentrations of Alexa Fluor 488 (10 $\mu \mathrm{mol} / \mathrm{L}$ RNA); (d) fluorescence images of lotion for different washing times

记效率, 公式如下: 标记效率 $(\mathrm{LE})=[$ 染料 $(\mu \mathrm{mol} / \mathrm{L})] /$ $[$ 探针 $(\mu \mathrm{mol} / \mathrm{L})]$; [探针 $(\mu \mathrm{mol} / \mathrm{L})]=\left(1000 / \mathrm{MW}_{\mathrm{RNA}}\right) \times$ $\left[\mathrm{RNA}\left(\mu \mathrm{g} \mathrm{mL}^{-1}\right)\right]$, 其中, $\mathrm{MW}_{\mathrm{RNA}}$ 为单股 RNA的近似分 子量, $\mathrm{MW}_{\mathrm{RNA}}=$ 核苷酸的数量 $\times 303.7\left(\mathrm{~g} \mathrm{~mol}^{-1}\right)$.

(ii) 原位杂交. 取过夜培养菌接种到 $20 \mathrm{~mL}$ LB液体培养基中, E. coli MG1655菌液中不加抗生素, $\Delta s g r S$ 菌液中加人卡那震素, $\Delta s g r S-p B A D-S g r S$ 菌液中 加人卡那需素、氨芐霉素, 当菌液 $A_{600}$ 达到 $0.3 \sim 0.4$ 时, 将菌液倒人离心管中并预冷, $4^{\circ} \mathrm{C}$ 条件下 $4500 \times g$ 离心 5 min收集沉淀, 再用 $1 \mathrm{~mL} 4 \%$ 甲醛重悬, 室温下旋转 混合 $30 \mathrm{~min}$ 固定细菌, 然后 $400 \times g$ 离心 $10 \mathrm{~min}$ 收集沉 淀, PBS洗两次, $300 \mu \mathrm{L}$ RNAse Free Water重悬沉淀, 先加入 $350 \mu \mathrm{L}$ 无水乙醇混匀, 再加人 $350 \mu \mathrm{L}$ 无水乙 醇混匀, 得到终浓度 $70 \%$ 乙醇, 室温旋转混合至少 $1 \mathrm{~h}$ 或 $4^{\circ} \mathrm{C}$ 放置至少一周, 使细胞膜变得通透.

取透化作用后的菌液 $300 \mu \mathrm{L}$, 离心弃去上清液, 其余的样品放置在 $4^{\circ} \mathrm{C} .1 \mathrm{~mL} 40 \%$ 洗液重悬沉淀. 取 $50 \mu \mathrm{L}$ 预热至室温的 $40 \%$ 杂交液加到上述离心管中, 将 $10 \mu \mathrm{mol} / \mathrm{L}$ 的探针溶液各取 $5 \mu \mathrm{L}$ 加到杂交溶液中混 匀, 离心弃去上清液. 再用杂交液和探针的混合液重 悬沉淀, $30^{\circ} \mathrm{C}$ 杂交炉中杂交过夜. 然后, 取 $40 \%$ 洗液
$200 \mu \mathrm{L}$ 加到杂交样品中混匀, 低速离心收集沉淀, 洗 涤3次. 每次洗涤时把样品放 $30^{\circ} \mathrm{C}$ 杂交炉孵育 $30 \mathrm{~min}$ 再离心. 最后用 $3 \mu \mathrm{L} 2 \times \mathrm{SSC}$ 重悬细菌, 显微镜下成像.

（iii） smFISH方法的优化. E. coli MG1655, $\Delta s g r S, \Delta s g r S$-pBAD-SgrS 3株菌按照常规smFISH方法 操作, 9条标记Alexa Fluor 488的探针进行杂交定位 SgrS. 另外, 取 $3 \mu \mathrm{L} 5 \mu \mathrm{g} \mathrm{mL}^{-1}$ Alexa Fluor 488染料 加到 E. coli MG1655进行杂交作为阴性对照. 相同设 定条件下Olympus FV-1000共聚焦显微镜观察成像 (63×), 使用 Olympusfluoview ver. $4.0 \mathrm{~b}$ viewer 和 Microsoft Visio 2010处理图片.

洗涤次数的确定: 杂交后洗涤时保留上清液, BIO-RAD凝胶成像分析系统拍照观察。防淬灭剂的 选择: 按照常规smFISH操作步骤进行, 分别使用自制 的90\%甘油和SlowFade ${ }^{\circledR}$ Diamond Antifade Mountant 滴加到样品上, 防止苂光淬灭. 不同杂交温度的比 较: 杂交温度分别为 $30,40,50^{\circ} \mathrm{C}$, 使用合适的封片 剂，其余按照常规smFISH操作步骤进行. 不同杂交 时间的比较：以最佳的杂交温度进行杂交，杂交时间 分别为 $1,3,5$ 和 $7 \mathrm{~h}$, 使用合适的封片剂, 其余按照常 规smFISH操作步骤进行. 探针的处理：探针经 $98^{\circ} \mathrm{C}$ 
变性 $10 \mathrm{~min}$, 立即放冰上防止复性, 再以最优条件进 行 smFISH操作. 3株菌在不同条件下 SgrS定位成像, 以 $\Delta s g r S$ 绿色苂光强度最低, $\Delta s g r S-p B A D-S g r S$ 和 $E$. coli MG1655绿色苂光强度明显为判定依据.

(iv) Alexa-555 WGA的操作流程. 按照优化的 条件, 观察不同步骤细菌的细胞壁染色结果, 确定最 佳的操作步骤. 流程 1: $\Delta s g r S$-pBAD-SgrS 固定洗涤 后, 加人 $100 \mu \mathrm{L}$ Alexa-555 WGA $\left(5 \mu \mathrm{g} \mathrm{mL}^{-1}\right)$ 染料室 温孵育 $10 \mathrm{~min}$, 取 $1 \mu \mathrm{L}$ 涂片观察; 再根据常规流程进 行操作, 采用70\%乙醇和Triton X-100两种溶液透化、 预杂交和杂交, 每一步骤结束后取 $1 \mu \mathrm{L}$ 涂片观察. 流 程2: $\Delta s g r S$-pBAD-SgrS按照常规smFISH操作步骤进 行, 最后加人 $100 \mu \mathrm{L}$ Alexa-555 WGA $\left(5 \mu \mathrm{g} \mathrm{mL}^{-1}\right)$ 染 料室温孵育 $10 \mathrm{~min}$, 取 $1 \mu \mathrm{L}$ 涂片观察.

( V ) smFISH超分辨成像. 以优化条件定位 $E$. coli MG1655中 SgrS, 最后加人浓度 $20 \mu \mathrm{g} \mathrm{mL}$ 的 Hoechst 33342室温染色 $20 \mathrm{~min}, \mathrm{~N}-\mathrm{SIM}$ 超分辨率显微 镜成像(100×). E. coli MG1655, $\Delta s g r S$ 和 $\Delta s g r S$-pBAD$\mathrm{SgrS}$ 按照优化的 smFISH操作步骤进行杂交, 相同设 定条件下 N-SIM超分辨率显微镜观察成像 $(100 \times)$. 使 用NIS-Elements Viewer 4.20处理图片.

\section{2 结果和分析}

\section{1 菌株构建}

(i ) 敲除株 $\Delta s g r S$ 的鉴定. 通过 $\operatorname{SgrS}$ 外引物以 及外引物同卡那盒鉴定引物交叉配对鉴定敲除株的 正确性, 氨苄盒鉴定引物进行消除pKD46质粒后的 鉴定. 结果可见, 第一对交叉引物敲除株有 $537 \mathrm{bp}$ 的 条带; 第二对交叉引物敲除株有912 bp的条带, 交叉 引物的鉴定证明同源替换部分准确; 外部引物敲除 株有 1685 bp的条带, 野生株有367 bp的条带; pKD46 鉴定引物扩增的敲除株没有条带, 野生株有 $479 \mathrm{bp}$ 的 条带; 阴性对照以水为模板扩增, 没有出现条带. 图 中条带的大小均与预期一致, 表明 $\Delta \mathrm{s} g r S$ 敲除株构建 成功并消除pKD46质粒(图2).

(ii ) 表达株 $\Delta s g r S$-pBAD-SgrS的鉴定. 载体空 质粒和鉴定正确的过表达质粒pBAD-SgrS分别电转 至 $\Delta s g r S$ 敲除株, 挑取单克隆进行 PCR鉴定, 设阴阳 性以及空载体对照, 结果显示, 阴性对照、空载体 $\Delta s g r S$-pBAD对照均未扩增出条带, $\Delta s g r S-\mathrm{pBAD}$ $\operatorname{SgrS}$ 过表达株和阳性对照出现227 bp 的条带(图3),

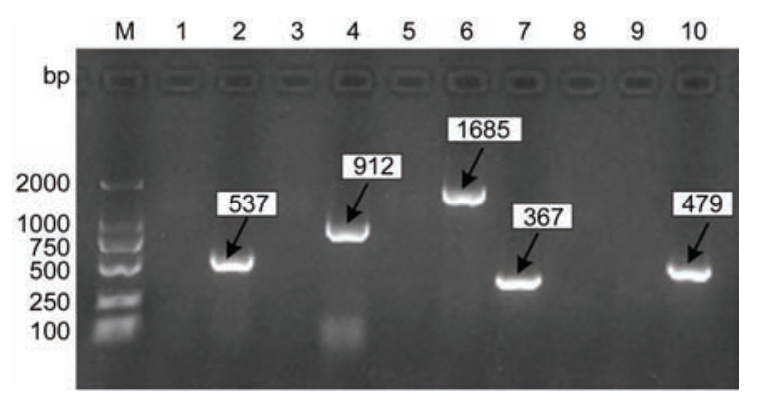

图 2 SgrS高除株构建及pKD46 质粒消除鉴定. M. DL 2000 DNA Marker. 1 2: SgrS-I-F/Kan-I-R; 1: 阴性对照; 2: SgrS; 3 4: Kan-I-F/ SgrS-I-R; 3: 阴性对照; 4: $\Delta s g r S ; 5 \sim 7$ : SgrS-I-F/SgrS-I-R; 5: 阴性对 照; 6: SgrS; 7: WT; 8 10: pKD46-F/pKD46-R; 8: 阴性对照; 9: SgrS; 10: WT (pKD46)

Figure 2 Identification of SgrS pKD46-cured. M. DL 2000 DNA Marker. 1-2: SgrS-I-F/Kan-I-R; 1: negative control; 2: SgrS; 3-4: Kan-IF/SgrS-I-R; 3: negative control; 4: $\Delta s g r S$; 5-7: SgrS-I-F/SgrS-I-R; 5 : negative control; 6: SgrS; 7: WT; 8-10: pKD46-F/pKD46-R; 8: negative control; 9: SgrS; 10: WT (pKD46)

表明此过表达株构建成功. 制备高质量的地高辛标 记的RNA探针, Northern blot方法验证菌株诱导过表 达成功.

\section{2 smFISH方法的建立.}

(i) 探针的标记效率. Nano drop 2000测定探 针和标记染料的浓度, 柱形图分析染料的菼光浓度, 可见SgrS5的浓度最高为 $15 \mu \mathrm{mol} / \mathrm{L}, \mathrm{SgrS} 1$ 和SgrS4的 浓度最低, 不到 $9 \mu \mathrm{mol} / \mathrm{L}$ (图1(c)). 根据测得的RNA $\left(\mu \mathrm{g} \mathrm{mL}^{-1}\right)$ 和染料 $(\mu \mathrm{mol} / \mathrm{L})$ 结果, 结合公式计算染料的 标记效率, 结果显示, 9 条探针的标记效率与测定的 染料浓度成正比, 除了 SgrS4 为 76\%外, 其余均在 $80 \%$ 以上.

(ii) 洗涤上清液的菼光结果. 不同洗涤次数菼 光强度不同, 洗涤上清液的苂光随着次数的增加而 逐渐减弱, 到第 5 次时达到最低, 因此, 洗涤 5 次最佳 (图1(d)).

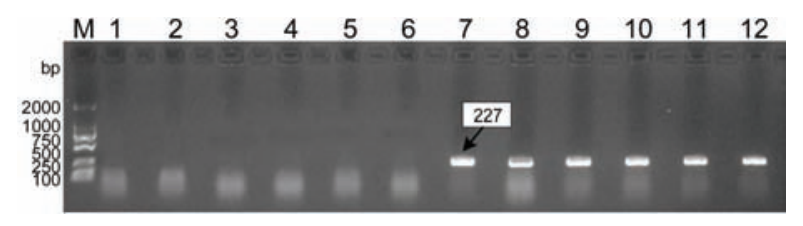

图 3 过表达株 $\Delta s g r S-p B A D-S g r S$ 的鉴定. M. DL 2000 DNA Marker. 1: 阴性对照; 2 6: $\Delta s g r S$-pBAD; 7 11: $\Delta s g r S-p B A D-S g r S ; ~ 12:$ 阳性对照

Figure 3 Identification of overexpression $\Delta s g r S$-pBAD-SgrS. M. DL 2000 DNA Marker. 1: Negative control; 2-6: $\Delta s g r S-p B A D ; 7-11$ : $\Delta s g r S$-pBAD-SgrS; 12: positive control 
（iii）封片剂的确定. b组过表达株 $\Delta s g r S-p B A D-$ $\operatorname{SgrS}$ 的绿色苂光强度高于 $\mathrm{a}$ 组, 防淬灭封片剂的封 片效果(图4(b))明显优于自制的90\%甘油(图4(a)), 确 定SlowFade ${ }^{\circledR}$ Diamond Antifade Mountant为合适的封 片剂。

(iv) 杂交温度的确定. 比较3组图片, 发现随 着杂交温度的提高, 绿色苂光信号越来越弱 (图 4(c) (e)). $30^{\circ} \mathrm{C}$ 杂交, $\Delta \operatorname{sgrS}$ 有非特异的结合, 绿色苂 光信号明显, 与 $E$. coli MG1655差别不大, 过表达株 $\Delta s g r S$-pBAD-SgrS信号最强(图4(c)); $40^{\circ} \mathrm{C}$ 杂交, $\Delta s g r S$ 苂光信号与 E. coli MG1655均表现较弱的绿色荧光, $\Delta s g r S$-pBAD-SgrS信号较强(图4(d)); $50^{\circ} \mathrm{C}$ 杂交, 3 株菌 苂光信号均最弱(图4(e)). 因此, 选择 $\Delta s g r S$ 苂光信号 比较弱, 而过表达株信号较强的 $40{ }^{\circ} \mathrm{C}$ 杂交为最佳温度.

( V ) 杂交时间的确定. 整体观察f, g, h, i 4 组
菌，苂光信号强度表现先弱后强的趋势. 杂交 $1 \mathrm{~h}$, $\Delta \operatorname{sgrS}$ 苂光最强, 其他两株菌没有明显的差异性(图 4(f)); 杂交3 h, $\Delta s g r S$ 荧光最弱, 表明非特异吸附少, 其余两株信号差别不大(图4 $(\mathrm{g})$ ); 杂交 $5 \mathrm{~h}, \Delta s g r S$ 显示 明亮苂光, 表明有非特异结合, 野生株信号与敲除株 差别不大，过表达株反而减弱(图4(h)); 杂交7 h, 3株 菌苂光强度差别不大, 但对应株强度均高于杂交 $5 \mathrm{~h}$ 的结果, 表明随着时间的延长, 信号强度有上升的趋 势, 但是敲除株的非特异结合同样也存在(图4(i)). 最终确定 $3 \mathrm{~h}$ 为最佳杂交时间.

(vi) 探针的处理. 探针经 $98^{\circ} \mathrm{C}$ 变性 $10 \mathrm{~min}$ 以消 除二级结构, 减少非特异结合. 结果显示, 3 株菌整体 信号比较弱, 但是标记的光点更为集中, 不同于 $\mathrm{g}$ 组 大面积弥散状的绿色苂光(图4(j)). 因此, 确定探针 需要 $98^{\circ} \mathrm{C}$ 变性处理 $10 \mathrm{~min}$. (a)

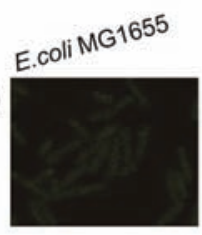

(b)

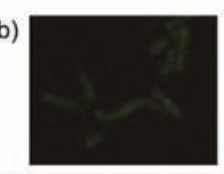

(c)

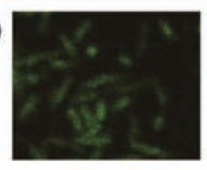

(d)

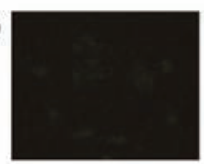

(e)

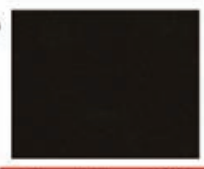

(k)

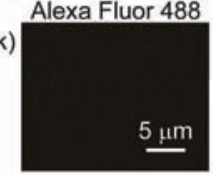

$\mu \mathrm{m}$
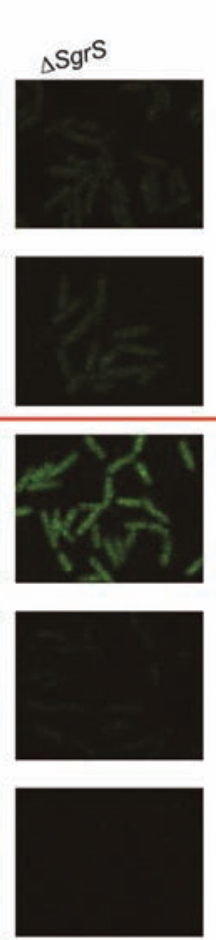
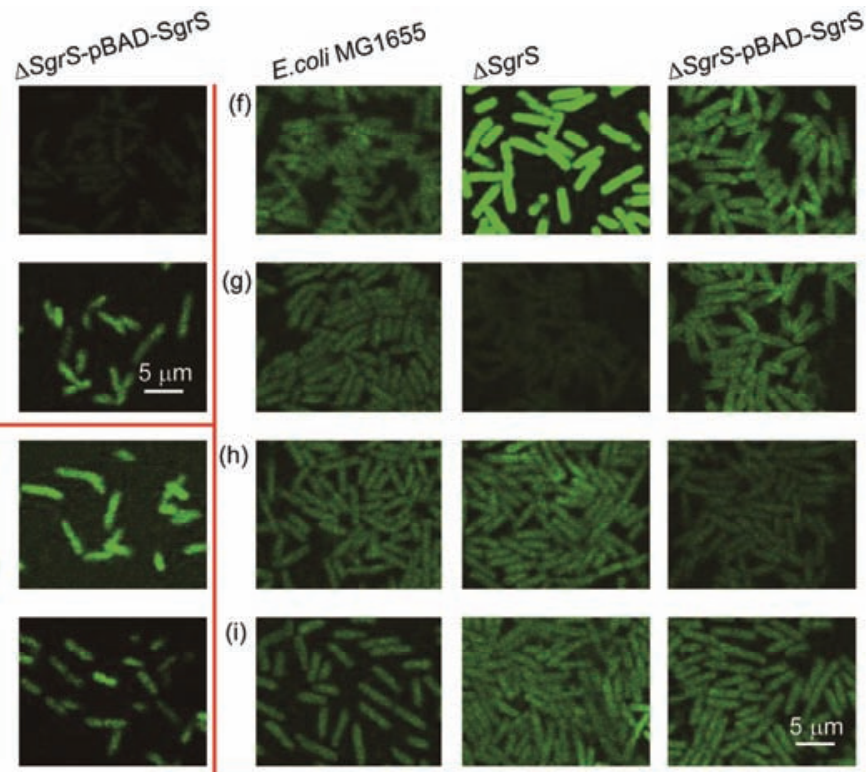

(j)
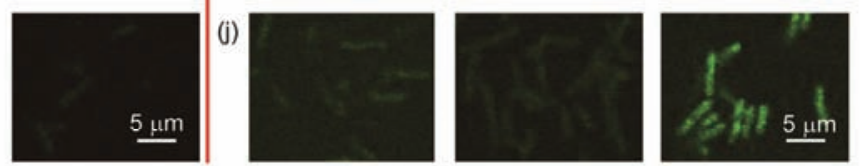

图 4 (网络版彩色) smFISH条件优化. (a) $90 \%$ 甘油; (b) SlowFade ${ }^{\circledR}$ Diamond Antifade Mountant; (c) $30^{\circ} \mathrm{C}$ 杂交; (d) $40^{\circ} \mathrm{C}$ 杂交; (e) $50^{\circ} \mathrm{C}$ 杂交; (f) 杂 交 $1 \mathrm{~h} ;(\mathrm{g})$ 杂交 $3 \mathrm{~h}$; (h) 杂交 $5 \mathrm{~h}$; (i) 杂交 $7 \mathrm{~h}$; (j) $98^{\circ} \mathrm{C}$ 变性 $10 \mathrm{~min}$; K. Alexa Fluor 488 对照

Figure 4 (Color online) Optimization of smFISH conditions. (a) $90 \%$ glycerol; (b) SlowFade ${ }^{\circledR}$ Diamond Antifade Mountant; (c) $30^{\circ} \mathrm{C}$; (d) $40^{\circ} \mathrm{C}$; (e) $50^{\circ} \mathrm{C}$; (f) $1 \mathrm{~h}$; (g) $3 \mathrm{~h}$; (h) $5 \mathrm{~h}$; (i) $7 \mathrm{~h}$; (j) degeneration for $98^{\circ} \mathrm{C} 10 \mathrm{~min}$; K. Alexa Fluor 488 
（vii）阴性对照. 相同拍照条件下, E. coli MG1655 使用未标记探针的Alexa Fluor 488染料杂交, 没有出 现肉眼可见的绿色菼光(图4(k)).

(viii) Alexa-555 WGA标记细胞壁. 固定后染细 胞壁, 细菌的轮廓清晰可见, 经预杂交、杂交后每步 再涂片观察, 不见红色苂光, 只显示杂交的绿色苂 光. 按照优化的程序杂交后, 最后定位细胞壁, 结果 可见细菌的清晰结构, 红色苂光显示细菌的轮廓, 绿 色苂光分布在胞浆中, 达到了预期的效果(图5). 因 此, 确定操作步骤为: 固定-洗涤-透化-预杂交-杂交洗涤-染细胞壁-洗涤-涂片.

（iX） N-SIM超分辨率显微镜成像. N-SIM超分 辨率显微镜观察, E. coli MG1655中Hoechst 33342标 记拟核为蓝色, SgrS呈现绿色定位于胞浆中(图6(a)). 3 株菌在相同设定条件下 N-SIM超分辨率显微镜成像, $\Delta s g r S$ 不见绿色苂光, $\Delta s g r S-p B A D-S g r S$ 的绿色苂光点 多于 E. coli MG1655, 3株菌的轮廓均显示红色, 与预 期结果一致. smFISH技术结合Alexa-555 WGA染料 对细菌细胞壁的标记, 完整地呈现了细菌的形态. 被 定位的 $\mathrm{SgrS}$ 显示绿色苂光, 呈颗粒状在细菌胞浆中 弥散分布, 而使用Olympus FV-1000共聚焦显微镜观

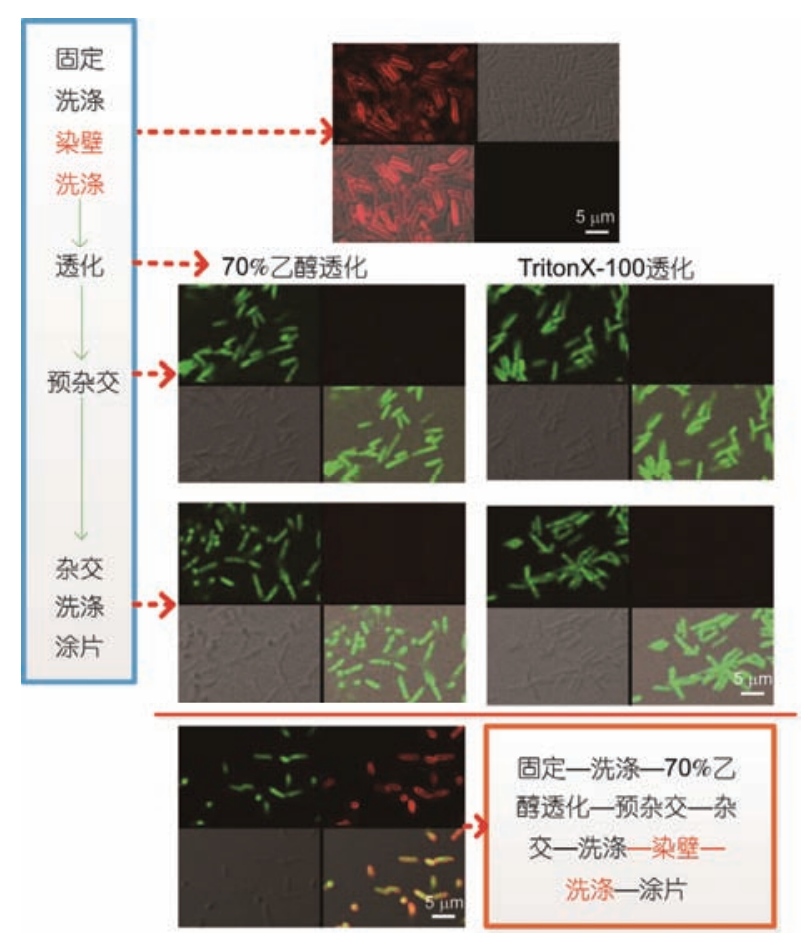

图 5 (网络版彩色) Alexa-555 WGA的操作流程

Figure 5 (Color online) Operation process for Alexa-555 WGA
察成像时, 细菌胞浆整体呈现绿色, 无法分辨定位结 果, 超分辨率显微镜清晰地定位了 SgrS 在细菌中的 分布(图6(b)).

\section{3 讨论}

E. coli MG1655是大肠杆菌的模式菌株, 在这株 菌基础上进行敲除和过表达小RNA SgrS. smFISH技 术能报告转录本丰度, 在建立 smFISH方法条件摸索 过程中, 敲除株作为阴性对照菌株, 过表达株作为阳 性对照菌株, 以此作为条件优化的依据. 因此, 选择 E. coli MG1655, $\Delta s g r S, \Delta s g r S$-pBAD-SgrS 3株菌为供 试菌株. 为了增加 smFISH杂交的特异性, 提高苂光 信号强度, 本研究在初步确定操作步骤后, 优化每步 的条件, 得出结论: 杂交后适宜洗涤 5 次, 以 Slow Fade Diamond Antifade Mountant作为封片剂, $40^{\circ} \mathrm{C}$ 杂 交 $3 \mathrm{~h}$, 探针需要经 $98^{\circ} \mathrm{C}$ 变性 $10 \mathrm{~min}$, 杂交完成后加 人Alexa-555 WGA染料可以定位细菌的细胞壁.

smFISH杂交条件有的报道为 $30^{\circ} \mathrm{C}$ 过夜 ${ }^{[13,14]}$, 有 的报道为 $37^{\circ} \mathrm{C}$ 过夜 ${ }^{[7,15]}$, 本文以敲除株为阴性对照菌 株, 减少特异性结合为原则, 设定 $30,40,50^{\circ} \mathrm{C} 3$ 个 杂交温度, 1, 3, 5, $7 \mathrm{~h} 4$ 个杂交时间, 确定最佳杂交条 件为 $40^{\circ} \mathrm{C}, 3 \mathrm{~h}$, 与文献报道的 $37^{\circ} \mathrm{C}, 3 \mathrm{~h}$ 相似 ${ }^{[16]}$. 分析 认为, 较高的温度有利于探针与目的片段的结合, 但 是温度过高, 破坏了细菌内部的结构, 不能准确定位 目的基因; $1 \mathrm{~h}$ 杂交时间过短，探针与目的基因结合不 充分, 造成非特异性吸附偏高, 超过 $3 \mathrm{~h}$, 随着杂交时 间的延长, 非特异结合又有所增加.

关于探针, Fei等人 ${ }^{[13]}$ 在 $s m F I S H$ 方法中使用的是 DNA探针, 本研究设计合成RNA探针, 杂交前探针 经 $98^{\circ} \mathrm{C}$ 变性处理 $10 \mathrm{~min}$, 消除探针本身的二级结构, 增强了与目的基因结合的特异性. 研究中, 尝试使用 标记效率最高的SgrS5单条探针定位 $\mathrm{SgrS}$, 单条探针 也可实现对目的基因定位，但是需要延长曝光时间, 杂交后拍照曝光时间为 $1 \mathrm{~s}, 9$ 条探针同时标记拍照时, 曝光时间是单条的 $1 / 10$, 为 $100 \mathrm{~ms}$. 较长的曝光时间 使得染料容易发生淬灭, 不利于观察后拍照. SgrS5 单条探针在敲除株中杂交结果也显示较强的苂光, 表明单条探针标记效果差, 增加标记的条数能提高 结合的特异性. SmFISH作为一项新的定位技术, 目 前还没有统一的评价标准, 灵敏性主要受显微镜的 分辨率和标记探针信号强度的影响. 由于本研究中 合成的不同RNA探针标记效果不同，对方法灵敏度 
(a)
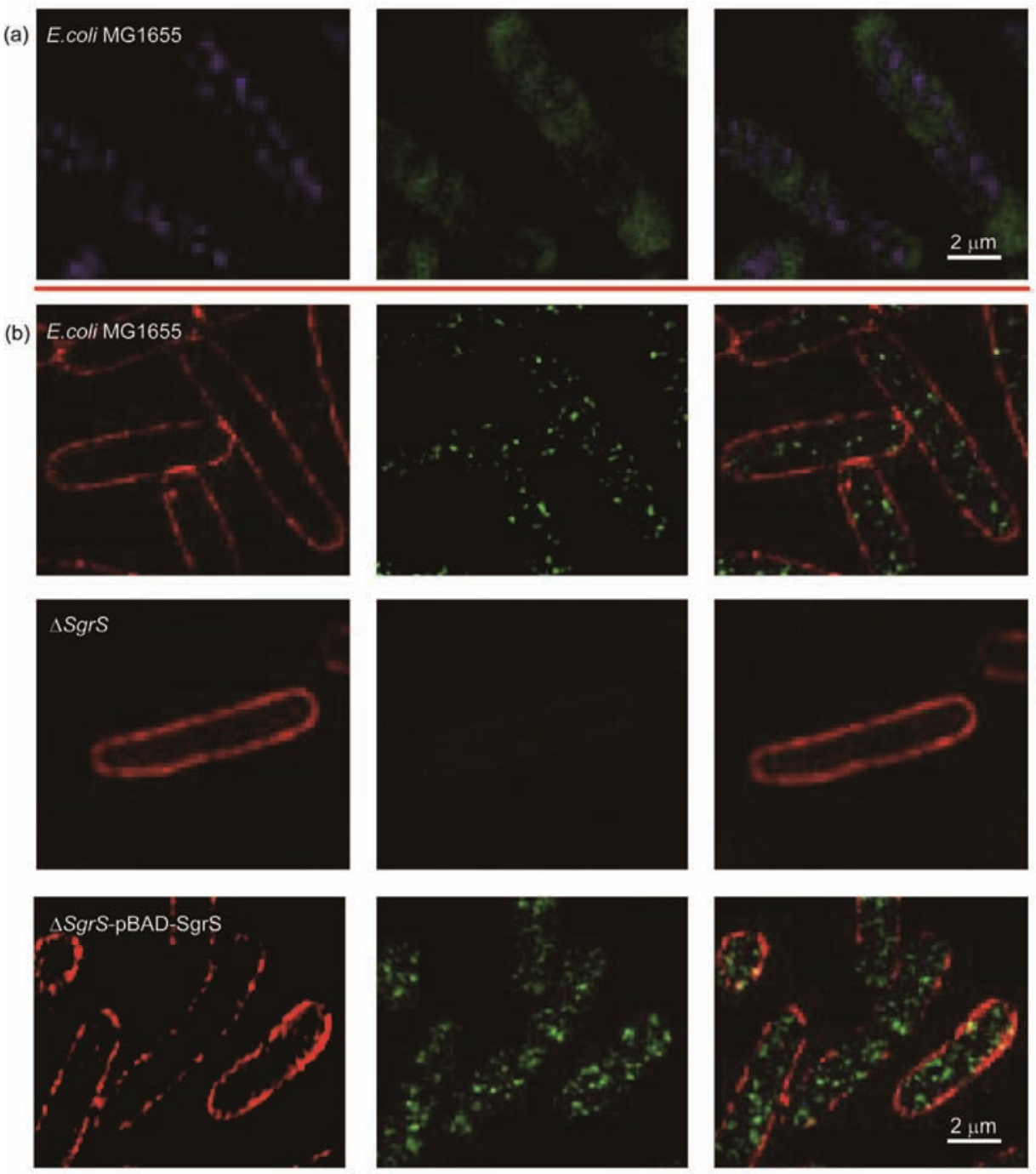

图 6 (网络版彩色) N-SIM超分辨率显微镜成像. (a) E. coli MG1655 中SgrS与拟核的相对位置; (b) E. coli MG1655, $\Delta$ sgrS和 $\Delta$ sgrS-pBAD-SgrS三 株菌的SgrS定位结果

Figure 6 (Color online) Imaging by N-SIM super-resolution microscopy. (a) The correspond positions of SgrS and nucleus of $E$. coli MG1655; (b) The SgrS localization of E. coli MG1655, $\Delta$ sgrS and $\Delta$ sgrS-pBAD-SgrS

的评价造成了一定的困难. 随着RNA标记方法的进 步, RNA探针菼光标记的敏感性会不断改善. 2014年, Eric Betzig, Stefan W. Hell和William E. Moerner 3位 科学家因超分辨技术获得诺贝尔化学奖, 此技术目 前正朝着更快、更精和更高的方向迈进, smFISH技术 的灵敏性也将逐步提高.

定位小RNA操作过程要严格, 防止RNA探针降 解, 每步操作需要使用去RNA酶材料及试剂. 杂交 液配方用量以及成分均关系着杂交的特异性及灵敏 度. 本研究中各成分的作用为: 去离子甲酰胺的浓度 影响杂交信号, 甲酰胺的浓度越高, 杂交的特异性越
好, 但是甲酰胺的浓度过高又使得阳性样本信号偏 低，应适当选择甲酰胺的浓度 ${ }^{[17]}$; 硫酸葡聚糖可以 提高单链RNA探针与目的基因的杂交效率; SDS 是阴 离子表明活性剂, 具有良好的渗透和去污性能; 大肠 杆菌 tRNA的添加防止非特异结合，保证了杂交的特 异性; 核糖核苷氧钒基复合物为 RNA酶抑制剂, 可 以抑制酶活性, 防止RNA降解; BSA起到封闭作用, 减少非特异性吸附; SSC为柠檬酸钠缓冲液, 其中的 钠离子中和RNA链上的负电荷, 使其呈中性, 增强 了探针和靶序列的结合.

光学显微镜经历了宽场、共聚焦、全内反射以及 
超高分辨4个阶段, 使用共聚焦看到的成像图片, 定 位不明确, 整个细菌充满绿色苂光, 而超高分辨率显 微镜则不同, 能清晰准确地定位到每一个点, 其原理 在于, 成像时扣除定位点周围的光晕, 用光控制每幅 图像只有几个离散的光点, 几幅合成一张超高分辨 率的定位图片, 这样就避免了同时成像造成的互相 干扰 ${ }^{[18,19]}$. 超高分辨率显微镜成像是普通成像分辨 率的10 20倍, 克服了光学成像发生的衍射现象 ${ }^{[20,21]}$. 近两年，随着技术的不断进步，科学家们已将超分辨 技术应用于活组织、活细胞, 实现了高时空分辨活体

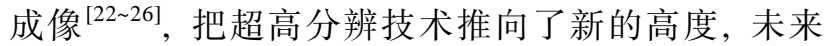
需要在拍照速度上加以改进, 短期内完成大样本量 的成像工作. 随着显微技术的不断提升, 将引导着研 究者去探索发现细胞的超微结构，从而揭示生命的 重要机制机理.

本研究建立的smFISH方法，把单分子原位杂交技 术与超分辨率显微镜结合, 成功地将 $\mathrm{SgrS}$ 定位于细菌 胞浆中, 实现了细菌中小RNA可视化定位，突破了因 低分辨率显微镜无法准确定位亚细胞的技术难题, 为 进一步研究小RNA在细菌中的调控机制奠定了基础.

\section{参考文献}

1 Jakt L M, Moriwaki S, Nishikawa S. A continuum of transcriptional identities visualized by combinatorial fluorescent in situ hybridization. Development, 2013, 140: 216-225

2 Osborne Nishimura E, Zhang J C, Werts A D, et al. Asymmetric transcript discovery by RNA-seq in C. elegans blastomeres identifies neg-1, a gene important for anterior morphogenesis. PLoS Genet, 2015, 11: e1005117

3 Buganim Y, Faddah D A, Cheng A W, et al. Single-cell expression analyses during cellular reprogramming reveal an early stochastic and a late hierarchic phase. Cell, 2012, 150: 1209-1222

4 Tan R Z, van Oudenaarden A. Transcript counting in single cells reveals dynamics of rDNA transcription. Mol Syst Biol, 2010, 6: 358

5 Oka Y, Sato T N. Whole-mount single molecule FISH method for zebrafish embryo. Sci Rep, 2015, 5: 8571

6 Gibson T M, Gersbach C A. Single-molecule analysis of myocyte differentiation reveals bimodal lineage commitment. Integr Biol (Camb), 2015, 7: 663-671

7 Chou Y Y, Heaton N S, Gao Q, et al. Colocalization of different influenza viral RNA segments in the cytoplasm before viral budding as shown by single-molecule sensitivity FISH analysis. PLoS Pathog, 2013, 9: e1003358

8 Singer Z S, Yong J, Tischler J, et al. Dynamic heterogeneity and DNA methylation in embryonic stem cells. Mol Cell, 2014, 55: 319-331

9 Sinsimer K S, Lee J J, Thiberge S Y, et al. Germ plasm anchoring is a dynamic state that requires persistent trafficking. Cell Rep, 2013, 5: 1169-1177

10 Yun Y R, Jeon E, Lee S, et al. Expression, purification, and characterization of a dentin phosphoprotein produced by Escherichia coli, and its odontoblastic differentiation effects on human dental pulp cells. Protein J, 2012, 31: 504-510

11 Kang W, Kim S, Lee S, et al. Characterization and optimization of vascular endothelial growth factor(165) (rhVEGF(165)) expression in Escherichia coli. Protein Expr Purif, 2013, 87: 55-60

12 Hancock V, Ferrières L, Klemm P. Biofilm formation by asymptomatic and virulent urinary tract infectious Escherichia coli strains Fems Microbiol Lett, 2007, 267: 30-37

13 Fei J, Singh D, Zhang Q, et al. RNA biochemistry. Determination of in vivo target search kinetics of regulatory noncoding RNA. Science, 2015, 347: 1371-1374

14 So L H, Ghosh A, Zong C, et al. General properties of transcriptional time series in Escherichia coli. Nat Genet, 2011, 43: 554-560

15 Friedman L G, Riemslagh F W, Sullivan J M, et al. Cadherin-8 expression, synaptic localization, and molecular control of neuronal form in prefrontal corticostriatal circuits. J Comp Neurol, 2015, 523: 75-92

16 Zhang X, Song Y, Shah A Y, et al. Quantitative assessment of ratiometric bimolecular beacons as a tool for imaging single engineered RNA transcripts and measuring gene expression in living cells. Nucleic Acids Res, 2013, 41: e152

17 Skinner S O, Sepulveda L A, Xu H, et al. Measuring mRNA copy number in individual Escherichia coli cells using single-molecule fluorescent in situ hybridization. Nat Protoc, 2013, 8: 1100-1113

18 Liu Z, Xing D, Su Q P, et al. Super-resolution imaging and tracking of protein-protein interactions in sub-diffraction cellular space. Nat Commun, 2014, 5: 4443

19 Ha T, Tinnefeld P. Photophysics of fluorescent probes for single-molecule biophysics and super-resolution imaging. Annu Rev Phys Chem, 2012, 63: 595-617

20 Johnson E, Seiradake E, Jones E Y, et al. Correlative in-resin super-resolution and electron microscopy using standard fluorescent proteins. Sci Rep, 2015, 5: 9583 
21 Requejo-Isidro J. Fluorescence nanoscopy: Methods and applications. J Chem Biol, 2013, 6: 97-120

22 Chen B C, Legant W R, Wang K, et al. Lattice light-sheet microscopy: Imaging molecules to embryos at high spatiotemporal resolution. Science, 2014, 346: 1257998

23 Godin A G, Lounis B, Cognet L. Super-resolution microscopy approaches for live cell imaging. Biophys J, 2014, 107: 1777-1784

24 Haas B L, Matson J S, DiRita V J, et al. Imaging live cells at the nanometer-scale with single-molecule microscopy: Obstacles and achievements in experiment optimization for microbiology. Molecules, 2014, 19: 12116-12149

25 Pan D, Hu Z, Qiu F, et al. A general strategy for developing cell-permeable photo-modulatable organic fluorescent probes for live-cell super-resolution imaging. Nat Commun, 2014, 5: 5573

26 Waldchen S, Lehmann J, Klein T, et al. Light-induced cell damage in live-cell super-resolution microscopy. Sci Rep, 2015, 5: 15348 


\title{
Development of the fluorescent imaging method of single- molecule sRNA SgrS in situ in Escherichia coli
}

\author{
WANG Jing ${ }^{1,2}$, HAN YanPing ${ }^{2 *} \&$ YANG RuiFu ${ }^{2}$ \\ ${ }^{1}$ College of Animal Science and Technology, Hebei North University, Zhangjiakou 075131, China; \\ ${ }^{2}$ State Key Laboratory of Pathogen and Biosecurity, Institute of Microbiology and Epidemiology, Academy of Military Medical Sciences, Beijing \\ 100071, China \\ * Corresponding author, E-mail: hypiota@hotmail.com
}

Single-cell gene expression studies could not only provide the real-time information on intracellular amount and subcellular localization of RNA, but also could reveal the regulatory mechanism of bacterial variation, which cannot be obtained based on traditional view of bacterial populations. Owing to the application of green fluorescent protein (GFP) reporters, most of studies have mainly focused on proteins. Recently, the quantitative and localization of bacterial RNAs have been also implemented at single transcript level. All of the non-coding RNAs who function as crucial regulators of gene expression are called regulatory small RNAs (sRNA) in bacteria. Single molecular imaging techniques for labeling bacterial sRNA can be used to detect the activity and abundance of sRNA, which will help us to understand its regulatory mechanism and biological function.

SgrS, a conservative sRNA in $\gamma$-proteobacteria, is highly expressed under glucose-phosphate stress and involve in the sugar metabolism in bacteria. We chose $\mathrm{SgrS}$ as a model to establish the single-molecule fluorescence in situ hybridization (smFISH) method of RNA detection at the single-molecule level in Escherichia coli. It will be helpful for further studies on sRNA subcellular localization and gene regulation.

We used kanamycin resistance box replace $\operatorname{sgrS}$ to successful construct $\operatorname{sgrS}$ deletion mutant $\Delta \operatorname{sgr} S$ and subsequently cured the helper plasmid pKD46. The SgrS overexpression strain $\Delta$ sgrS-pBAD-SgrS was generated by introducing SgrS-overexpressed plasmid into the $\Delta \operatorname{sgrS}$ strains. E. coli MG1655, $\Delta \operatorname{sgrS}$ and $\Delta$ sgrS-pBAD-SgrS, all E. coli K-12 derivatives, were used in this study. The smFISH method on SgrS in E. coli was established. The optimal conditions are briefly stated as follows. The cells were fixed in $3.7 \%$ formaldehyde at room temperature for 30 minutes. Cells were permeabilized at $4{ }^{\circ} \mathrm{C}$ for overnight. Washed cells with $40 \%$ wash solution was resuspended in $40 \%$ hybridization buffer. The cells were centrifuged and resuspended in the hybridization buffer with $1 \mu \mathrm{M}$ sRNAs probes that denatured at $98^{\circ} \mathrm{C}$ for 10 minutes. Hybridization reactions were incubated in the hybridization oven at $40^{\circ} \mathrm{C}$ for 3 hours. The cells were washed five times with $40 \%$ wash solution. During wash, cells were resuspended and incubated at $40^{\circ} \mathrm{C}$ for 30 minutes. Cells were pelleted by $600 \times g$ centrifugation for 3 minutes, and the supernatant was removed. Cells were resuspended with $100 \mu \mathrm{L}$ of freshly prepared $5 \mu \mathrm{g} \mathrm{mL} \mathrm{m}^{-1}$ Alexa-555 WGA in $1 \times \mathrm{PBS}$, and incubated at room temperature for 10 minutes. Cells were pelleted by $600 \times g$ centrifugation for 3 minutes, and the supernatant was removed. The cells were resuspended in $5 \mu \mathrm{L}$ of $2 \times \mathrm{SSC}$. Then $1 \mu \mathrm{L}$ of sample and $1 \mu \mathrm{L}$ of SlowFade Diamond Antifade Mountant were pipetted to poly-L-lysine treated borosilicate chambered coverslip. A coverslip was placed on the sample. Super-resolution imaging was performed on Nikon inverted microscope with a 100× oil immersion objective. SgrS was indicated as green fluorescence granular with diffuse distribution in cytoplasm, while cellular wall images exhibited red fluorescence upon being stained with Alexa-555 WGA.

The combination of smFISH method and super-resolution microscopy techniques provides the potential clues and technical reference for further studies on revealing sRNA localization and sRNA-mediated regulatory mechanism.

Escherichia coli, sRNA SgrS, single-molecule fluorescence in situ hybridization (smFISH), super-resolution microscopy, Alexa-555 WGA

doi: 10.1360/N972017-00351 